\title{
SISTEM kWH METER DIGITAL MENGGUNAKAN MODUL PZEM-004T
}

\author{
Andriana \\ Fakultas Teknik, Jurusan Elektro \\ Universitas Langlangbuana \\ Jl. Karapitan 116, Bandung \\ Andriana6970@gmail.com \\ Zulkarnain \\ Fakultas Teknik, Jurusan Elektro \\ Universitas Langlangbuana \\ Jl. Karapitan 116, Bandung \\ zoe18990@gmail.com
}

\author{
Hadi Baehaqi \\ Fakultas Teknik, Jurusan Elektro \\ Universitas Langlangbuana \\ J1. Karapitan 116, Bandung \\ hbaehaqi@gmail.com
}

\begin{abstract}
Abstrak - Seiring dengan kebutuhan pemakaian listrik, konsumen perlu mengetahui jumlah pemakaian energi listrik yang dibutuhkan dalam setiap harinya. Untuk mengetahui jumlah pemakaian listrik adalah dengan cara mengukur energi listrik tersebut menggunakan alat pengukur energi listrik (electric meter). Perkembangan teknologi komunikasi sangatlah cepat, smartphone yang sedang digandrungi oleh masyarakat adalah smartphone yang berbasis sistem operasi android, selain fitur dan aplikasi yang sudah disediakan sistem operasi android sendiri bersifat sistem operasi open source. Alat monitoring pemakaian energi listrik berbasis operasi android menggunakan modul PZEM-004T adalah sebuah sistem yang dirancang dan dimanfaatkan untuk membaca jumlah pemakaian energi listrik yang meliputi tegangan, arus, daya aktif dan akumulasi energi. Alat monitoring dikoneksikan pada smartphone android yang digunakan sebagai media interface user yang menampilkan konsumsi energi listrik. Hasil pengujian menunjukkan bahwa alat monitoring pemakaian energi listrik menggunakan modul PZEM-004T dapat mengukur dan menampilkan nilai arus, tegangan, daya aktif serta akumulasi energi, selain itu alat monitoring pemakaian energi listrik menggunakan modul PZEM004T dapat memonitor secara real time serta tersimpan pada basis data. Berdasarkan hasil pengujian dapat disimpulkan bahwa hasil perancangan alat monitoring energi listrik memiliki angka simpangan (error) $0.29 \%$ untuk tegangan (volt), $4.63 \%$ untuk arus (ampere), $4.92 \%$ untuk daya aktif (watt) , $1.36 \%$ untuk $\cos \varphi$ dan $3.3 \%$ untuk perhitungan total energy dalam durasi 1 jam (watthour).
\end{abstract}

Kata kunci: Alat monitoring Energi, smartphone, energy meter, PZEM-004T.

\section{PENDAHULUAN}

Dewasa kini, listrik adalah salah satu kebutuhan primer manusia. Energi listrik adalah hasil dari segala proses konversi energi atas segala bentuk pembangkit listrik.

Energi listrik tidak dapat dibuat dengan mudah, perlu berbagai macam proses yang dibutuhkan untuk dapat membuat energi listrik yang sesuai dengan kebutuhan di lapangan. Mulai dari sistem pembangkitannya, proses sinkronisasinya, hingga bahan utama yang dibutuhkan sistem pembangkit untuk membangkitkan energi listrik, sehingga nilai dari energi listrik ini tidaklah murah.

Dalam skala rumah tangga, energi listrik biasa digunakan untuk kebutuhan berbagai macam beban elektronik seperti televisi, lampu, mesin cuci, dispenser, ataupun penanak nasi. Setiap beban elektronik tersebut memiliki tingkat energi yang berbeda-beda, semakin besar energi yang digunakan maka semakin besar juga biaya yang dibutuhkan untuk membayar energi listrik yang digunakan. Tanpa mengetahui energi yang digunakan setiap beban elektronik di setiap harinya, biaya yang perlu dikeluarkan untuk penggunaan energi listrik ini pun tak dapat diketahui secara pasti. Untuk mengantisipasi hal tersebut dibutuhkan suatu sistem monitoring untuk memantau konsumsi energi dari beban elektronik yang digunakan sehingga energi listrik dapat digunakan secara bijak.

Metode monitoring energi beban rumah tangga ini pun bermacam-macam, mulai dari penggunaan $\mathrm{kWH}$ meter hingga penggunaan mikroprosesor IC ADE 7752 seperti yang pernah diteliti oleh Muhammad Thoyib (2010). Penelitian lain dilakukan Mansur (2015) Metode monitoring daya listrik yang digunakan menggunakan sensor ACS712 dan bluetooth . Dalam kesempatan kali ini penulis menggunakan modul PZEM-004T untuk melakukan monitoring daya dan konsumsi energi listrik yang digunakan, hasil data tersebut dikirim ke android agar bisa langsung dimonitor dari jarak jauh. 


\section{METODE}

\subsection{Perancangan Alat}

Perancangan hardware terdiri dari Modul PZEM004T,Mikrokontroler, RTC (Real Time Clock), modul micro SD, LCD, modul NodeMCU ESP8266 dan Relay.Ada pun blok diagram rancangannya adalah sebagai berikut:

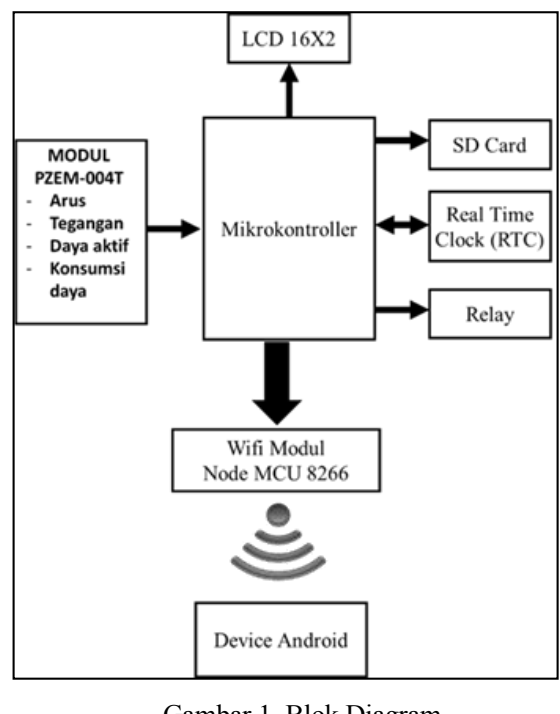

Keterangan dari blok diagram sistem adalah sebagai berikut:

1. Arus, tegangan, daya aktif dan konsumsi daya di baca oleh modul PZEM-004T.

2. Data arus, tegangan, daya aktif dan konsumsi daya kemudian diolah oleh mikrokontroler.

3. Data hasil pengolahan mikrokontroler selanjutnya ditampilkan pada LCD 16x2.

4. Data hasil pengolahan mikrokontroler juga dikirim ke SD card untuk disimpan.

5. Data hasil pengolahan mikrokontroler juga dikirim ke modul wifi NodeMCU ESP8266 untuk selanjutnya ditampilkan pada android.

6. Real Time Clock (RTC) melacak periode waktu agar sesuai dengan data yang diambil.

7. Relay dikendalikan menggunakan android.

\subsection{Perancangan Software}

Untuk membuat perangkat keras yang telah dibuat dapat berfungsi diperlukan perangkat lunak pada Arduino uno, NodeMCU ESP8266 dan Android. Perangkat lunak dikembangkan dengan bahasa $\mathrm{C}$ yang sudah dimodifikasi khas arduino yang dibuat pada arduino IDE pada komputer.

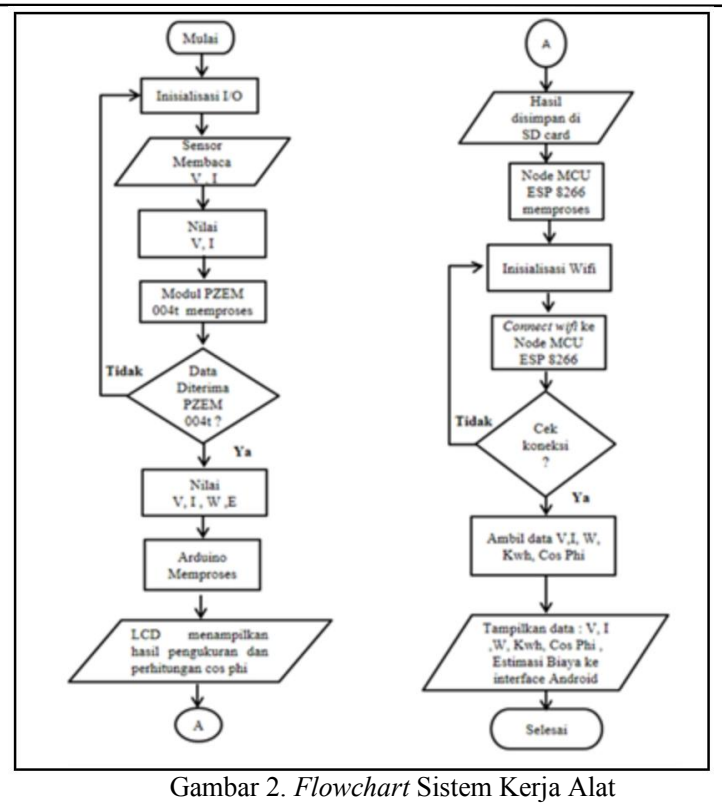

Penjelasan diagram alir yang ditunjukkan pada gambar 2 adalah sebagai berikut :

1. Jalankan program, lalu program akan melakukan inisialisasi sistem.

2. Sensor akan membaca arus dan tegangan.

3. Nilai data tersebut diolah oleh modul PZEM004T, dan menghasilkan 4 nilai keluaran yaitu arus, tegangan, daya aktif dan konsumsi daya.

4. Nilai keluaran dari modul PZEM-004T dikirim ke arduino uno.

5. Arduino uno mengolah nilai tersebut dan dilakukan perhitungan untuk menghasilkan nilai $\cos \varphi$.

6. Hasil dari pemrosesan data pada arduino dikirim ke :

a. Ditampilkan pada LCD berupa nilai arus, tegangan, daya aktif, konsumsi daya dan cos $\varphi$.

b. SD card untuk di simpan dalam bentuk txt.

c. Dikirim data arus, tegangan, daya aktif, konsumsi daya dan $\cos \varphi$ ke NodeMCU ESP 8266.

7. NodeMCU ESP 8266 mengirimkan data ke android melalui wifi.

8. Android menampilkan data : tegangan, arus, daya aktif,konsumsi daya, $\operatorname{Cos} \varphi$ dan estimasi biaya. 


\subsection{Perancangan Tampilan Android}

Display pada android adalah antarmuka yang berfungsi untuk menampilkan data hasil pengukuran . Tampilan android yang dirancang menggunakan software blynk. Gambar 3 menunjukkan tampilan pada android yang dibuat.

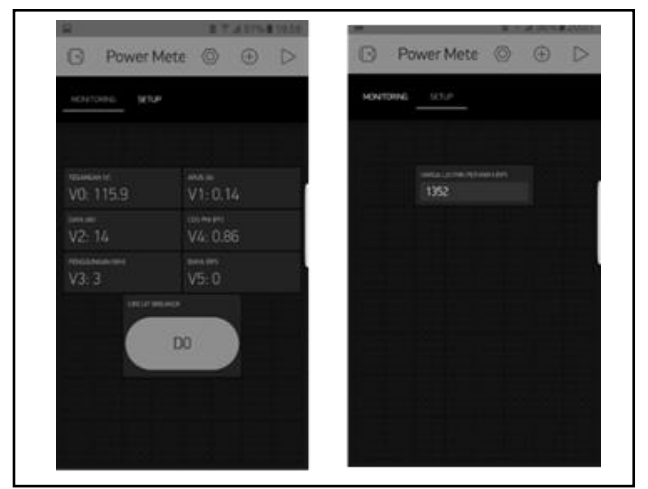

Gambar 3.Tampilan Android Sistem kWH Meter Digital

\section{HASIL DAN DISKUSI}

Pengukuran dan pengujian dilakukan terhadap bagianbagian dari sistem dan pengujian terhadap cara kerja sistem secara keseluruhan.

\subsection{Pengujian Sistem Keseluruhan}

Pengujian sistem secara keseluruhan merupakan pengujian sistem yang telah digabungkan secara utuh. Pengujian dilakukan dengan cara menghubungkan beban peralatan listrik yang akan di monitoring melalui stop kontak 220VAC yang telah disediakan pada modul alat ukur. Adapun sifat beban dari peralatan listrik yang akan diukur bersifat resistif, induktif dan kapasitif.

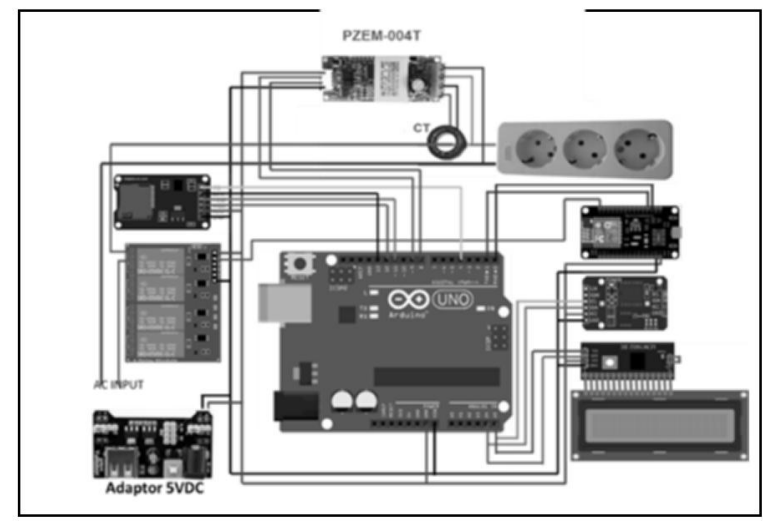

Gambar 4. Pengujian Sistem Keseluruhan
Tabel 1. Hasil Pengukuran

\begin{tabular}{|l|c|c|c|c|}
\hline \multicolumn{1}{|c|}{ Beban } & V & I & P & Cos $\Phi$ \\
\hline $\begin{array}{l}\text { TV Panasonic TH- } \\
\text { L42E5G 84 Watt }\end{array}$ & 205.10 & 0.29 & 55 & 0.94 \\
\hline $\begin{array}{l}\text { Setrika listrik National } \\
\text { No.NI -330E 1200W }\end{array}$ & 195.70 & 4.89 & 958 & 1 \\
\hline
\end{tabular}

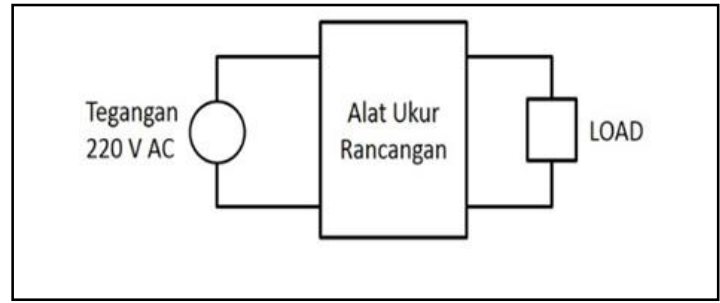

Gambar 5. Rangkaian Percobaan

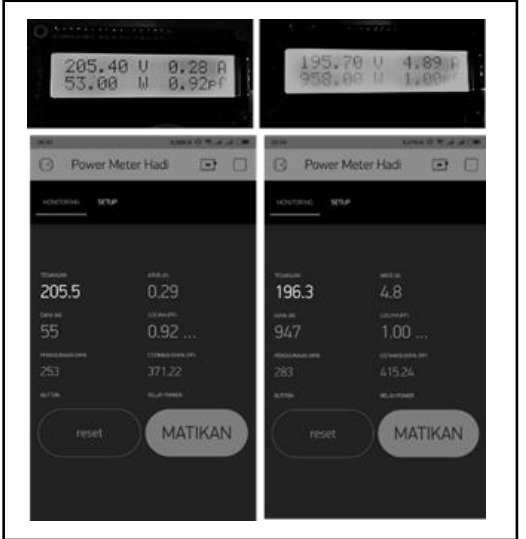

Gambar 6. Tampilan LCD Dan Android Hasil Uji Coba Secara Keseluruhan

\subsection{Pengujian Rangkaian Modul NodeMCU ESP8266.}

Pengujian modul NodeMCU ESP8266 bertujuan untuk mengetahui apakah modul tersebut dapat berkomunikasi melalui jaringan internet atau tidak.

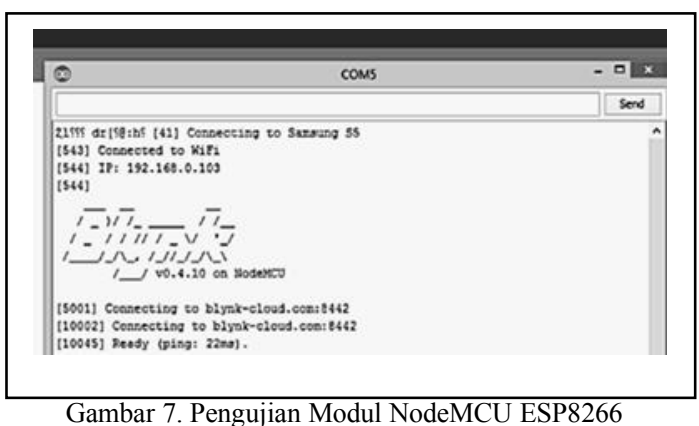


Hasil pengujian pada serial monitor terlihat jika modul NodeMCU ESP8266 dapat terhubung dengan sinyal wifi. Hal tersebut juga dapat terlihat pada deteksi unit yang terhubung dengan portable hotspot. Terlihat jika modul NodeMCU ESP8266 telah berhasil terhubung.

\subsection{Pengujian Relay}

Relay dalam sistem ini berfungsi untuk memutuskan sumber listrik ke beban. Relay dikendalikan secara manual melalui android. Jika tombol MATIKAN ditekan maka relay akan bekerja untuk memutuskan sumber listrik, dan display pada android berubah jadi NYALAKAN. Sumber listrik akan tersambung kembali jika kita menekan tombol NYALAKAN.

Tabel 2. Uji Coba Relay

\begin{tabular}{|c|c|c|c|}
\hline Beban & $\begin{array}{l}\text { Display pada android } \\
\text { sebelum relay dimatikan }\end{array}$ & $\begin{array}{l}\text { Display pada android } \\
\text { setelah relay dimatikan }\end{array}$ & Hasil \\
\hline $\begin{array}{l}\text { TV Panasonic } \\
\text { TH-L42E5G }\end{array}$ & 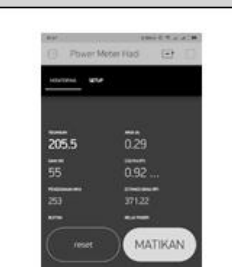 & 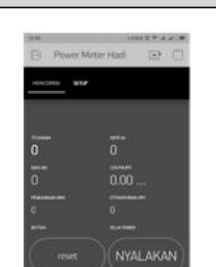 & Berhasil \\
\hline $\begin{array}{ll}\text { Setrika } & \text { listrik } \\
\text { National } & \text { No.NI } \\
-330 \mathrm{E} & \end{array}$ & 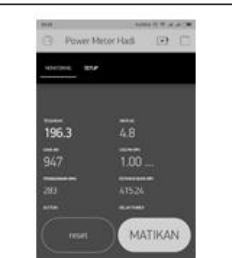 & 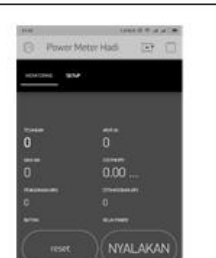 & Berhasil \\
\hline
\end{tabular}

Hasil pengujian pada relay tersebut dapat bekerja dengan baik, relay dapat menghungkan dan memutuskan sumber listrik ke beban. Hal tersebut dapat kita lihat pada display android dimana sebelum sumber listrik diputus tegangan, arus, daya aktif, $\cos \varphi$ dan konsumsi daya memiliki nilai sesuai yang terbaca oleh sensor. Setelah sumber listrik diputus maka semua parameter memiliki nilai nol.

\subsection{Pengujian Dibandingkan Dengan Alat Ukur Standar}

Setelah alat ukur rancangan dapat mengukur tegangan, arus , daya aktif dan konsumsi daya dari beban listrik, alat ukur ini membutuhkan perbandingan dengan alat ukur standar yang mengukur tegangan , arus dan daya aktif yang telah terkalibrasi.

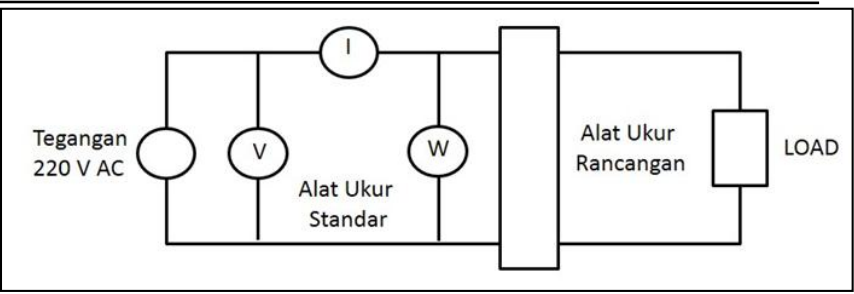

Gambar 8. Rangkaian Percobaan Pengukuran Menggunakan Alat Ukur Standar Dan Alat Ukur Rancangan

Tabel 3. Hasil pengujian dibandingkan dengan alat ukur standar

\begin{tabular}{|l|c|c|c|c|c|c|c|c|}
\hline \multirow{2}{*}{ Beban } & \multicolumn{5}{|c|}{ Alat ukur rancangan } & \multicolumn{5}{c|}{ Alat ukur standar } \\
\cline { 2 - 9 } & V(Volt) & I (A) & P(Watt) & Cos $\varphi$ & V(Volt) & I(A) & P(Watt) & Cos $\varphi$ \\
\hline $\begin{array}{l}\text { Setrika Listrik } \\
\text { Philips 300 W }\end{array}$ & 221.7 & 1.58 & 348 & 1 & 221.6 & 1.65 & 366 & 0.99 \\
\hline $\begin{array}{l}\text { Heater } \\
\text { Heles 520 W }\end{array}$ & 220.7 & 2.94 & 646 & 1 & 220.7 & 3.09 & 678 & 0.99 \\
\hline $\begin{array}{l}\text { AC } \\
\text { Samsung 600 W }\end{array}$ & 225.7 & 3.59 & 745 & 0.92 & 225.8 & 3.73 & 788 & 0.91 \\
\hline $\begin{array}{l}\text { TV } \\
\text { LG 55 W }\end{array}$ & 225.9 & 0.31 & 42 & 0.60 & 225.7 & 0.33 & 44 & 0.58 \\
\hline $\begin{array}{l}\text { Pompa Air } \\
\text { Shimizu 125 W }\end{array}$ & 225.5 & 1.25 & 270 & 0.95 & 222.4 & 1.34 & 281.3 & 0.94 \\
\hline
\end{tabular}

Tabel 4. Hasil pengujian dibandingkan dengan alat ukur standar

\begin{tabular}{|l|c|c|c|c|c|c|}
\hline \multirow{2}{*}{ Beban } & \multicolumn{3}{|c|}{ Alat ukur rancangan } & \multicolumn{3}{c|}{ Alat ukur standar } \\
& \multicolumn{3}{|c|}{$(w \mathrm{wH})$} \\
\cline { 2 - 7 } & $\begin{array}{l}\text { Meter } \\
\text { Awal }\end{array}$ & $\begin{array}{c}\text { Meter } \\
\text { Akhir }\end{array}$ & Selisih & $\begin{array}{c}\text { Meter } \\
\text { Awal }\end{array}$ & $\begin{array}{c}\text { Meter } \\
\text { Akhir }\end{array}$ & Selisih \\
\hline $\begin{array}{l}\text { Setrika Listrik } \\
\text { Philips 300 w }\end{array}$ & 206 & 218 & 12 & 0 & 11 & 11 \\
\hline $\begin{array}{l}\text { Heater } \\
\text { Heles 520 w }\end{array}$ & 218 & 276 & 58 & 11 & 73 & 62 \\
\hline $\begin{array}{l}\text { AC } \\
\text { Samsung 600 w }\end{array}$ & 276 & 280 & 4 & 73 & 77 & 4 \\
\hline $\begin{array}{l}\text { TV } \\
\text { LG 55 w }\end{array}$ & 280 & 317 & 37 & 77 & 116 & 39 \\
\hline $\begin{array}{l}\text { Pompa Air } \\
\text { Shimizu 125 w }\end{array}$ & 317 & 323 & 6 & 116 & 121 & 5 \\
\hline
\end{tabular}

\subsection{Nilai Simpangan (error) Alat Ukur Rancangan}

Setelah dilakukan pengambilan data pengukuran tegangan, arus, daya aktif dan konsumsi daya menggunakan alat ukur standar dan alat ukur rancangan, maka didapatkan tabel perhitungan simpangan (error) alat ukur rancangan dibanding alat ukur standar. Angka error dalam persen (\%) didapatkan dengan rumus: 
pengukuran alat ukur rancangan-pengukuran alat ukur standard pengukuran alat ukur standard

Setelah dihitung secara keseluruhan dan dirata-rata, maka nilai simpangan alat ukur rancangan terhadap alat ukur standar adalah $0.29 \%$ untuk tegangan (volt), 4.63 $\%$ untuk arus (ampere), $4.92 \%$ untuk daya aktif (watt), $1.36 \%$ untuk $\cos \varphi$ dan $3.3 \%$ untuk perhitungan total energi dalam durasi 1 jam (watthour).

\subsection{Perhitungan Daya Semu dan Faktor Daya}

Dari data pengukuran tegangan, arus dan daya aktif (watt), didapatkan hasil perhitungan daya semu (VA) dan faktor daya/ $\cos \varphi$. Sebagai contoh perhitungan, beban TV LG 55 Watt, jika arus terukur 0,31 Ampere saat dihubungkan dengan jaringan listrik 225,9 V AC (tegangan terukur), maka besar daya semu:

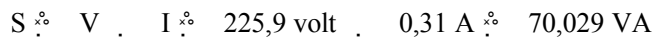

Dan diketahui daya aktif yang terukur pada saat dihubungkan dengan jaringan listrik yaitu 42 Watt, maka nilai faktor daya / $\cos \varphi$ beban tersebut sebesar:

$\operatorname{Cos} \Phi=\frac{P}{S}=\frac{42 \text { Watt }}{70,029 \mathrm{VA}}=0,6$

\section{KESIMPULAN}

Setelah melewati tahap perancangan dan pengujian alat rancangan, maka didapatkan beberapa kesimpulan sebagai berikut:

1. Alat monitoring pemakaian energi listrik menggunakan modul PZEM-004Tdapat mengukur dan menampilkan nilai arus, tegangan, daya listrik, faktor daya serta konsumsi energi.

2. Sistem kWH meter digital menggunakan modul PZEM-004T dapat memonitor secara real time.

3. Besar simpangan alat ukur rancangan terhadap alat ukur standar adalah $0.29 \%$ untuk tegangan (volt), $4.63 \%$ untuk arus (ampere), $4.92 \%$ untuk daya aktif (watt) , $1.36 \%$ untuk $\cos \varphi$ dan $3.3 \%$ untuk perhitungan total energi dalam durasi 1 jam (watthour).

4.Dikarenakan pendekatan angka meter hanya sampai bilangan satuan dan tidak ada angka di belakang desimal, maka perhitungan energy pada beberapa sampel percobaan menjadi kurang akurat.

\section{DAFTAR PUSTAKA}

[1] Sunanda, Wahri dan Irwan Dinata. 2003. "Implementasi Wireless Monitoring Energi Listrik Berbasis Web Database”. Jurnal Amplifier, ISSN: 2302 - 2949, Volume 04 Nomor 01.

[2] Pandiangan, Paken. 2003. "Ketidakpastian dan Pengukuran"

http://repository.ut.ac.id/4772/1/PEPA4203-M1.pdf. Diakses tanggal 18 Agustus 2018.

[3] Lister. 1998. "Mesin dan rangkaian listrik". Jakarta. Erlangga.

[4] Ajie, Sapta. 2016. "Belajar Arduino bagi pemula". http://saptaji.com/2016/11/09/belajar-arduino-bagipemula. Diakses tanggal 19 Agustus 2018.

[5] Al - maroghi, Fatkhiya Haadziq. 2015. "Sistem Monitoring Nomor Antrian di Puskesmas Menggunakan Aplikasi Android Berbasis Mikrokontroler". Surabaya. ITS.

[6] Akhmad, Hafezfahrizal. 2015. Alat ukur. http://ilmuhafez.blogspot.com/2015/10/materiwattmeter.html. Diakses tanggal 19 Agustus 2018.

[7] Idcloudhost. 2016. Mari Mengenal Apa itu Internet of Thing (IoT).

https://idcloudhost.com/mari-mengenal-apa-itu-internetthing-iot/. Diakses tanggal 19 Agustus 2018.

[8] Sora N.2017. Pengertian WiFi Dan Fungsinya Maupun Cara Kerjanya.

http://www.pengertianku.net/2017/08/pengertian-wifidan-fungsinya-maupun -cara-kerjanya.html. Diakses tanggal 19 Agustus 2018.

[9] Wikipedia. 2017. Tarip dasar listrik. https://id.wikipedia.org/wiki/Tarif dasar listrik. Diakses tanggal 19 Agustus 2018.

[10] Cekmas, Cekdin dan Barlian, Taupik. 2013. Rangkaian Listrik.Yogyakarta. Andi Yoyakarta.

[11] Github. 2016. PZEM004T.

https://github.com/olehs/PZEM004T. Diakses tanggal 19 Agustus 2018

[12] Atmel Datasheet. Mikrokontroler ATmega328. http://www.atmel.com/Images/Atmel-8271-8-bit-

AVRMicrocontroller. Diakses tanggal 18 Agustus 2018.

[13] Faudin, Agus . 2017.Tutorial Arduino mengakses module RTC DS3231.

https://www.nyebarilmu.com/tutorial-arduino-mengaksesmodule-rtc-ds3231/. Diakses tanggal 18 Agustus 2018.

[14] Tri Saputro, Tedy. 2017. Mengenal NODEMCU. https://embeddednesia.com/v1/tutorial-nodemcupertemuan-pertama/. Diakses tanggal 18 Agustus 2018

[15] Faudin, Agus .2018. Cara mengakses module micro SD menggunakan Arduino.

https://www.nyebarilmu.com/cara-mengakses-modulemicro-sd-menggunakan-arduino/. Diakses tanggal 19 Agustus 2018.

[16] Sejati, purnomo. 2011. Mengenal Komunikasi I2C(Inter Integrated Circuit). 
https://purnomosejati.wordpress.com/2011/08/25/mengen al-komunikasi-i2cinter-integrated-circuit/. Diakses tanggal 19 Agustus 2018.

[17] Eldas. 2012. LCD (Liquid Cristal Display) Dot Matrix 2x16 M1632.

http:/elektro nika-dasar.web.id/komponen/lcd-liquidcristal-display-dot-matrix-2x16-M1632/. Diakses tanggal 19 Agustus 2018.

[18] Dickson, K.2015. Pengertian Relay dan Fungsinya. http://teknikelektronika.com/pengertian-relay-fungsirelay/. Diakses tanggal 19 Agustus 2018.

[19] Faudin, Agus .2018. Mengenal aplikasi blynk untuk fungsi IoT. https://www.nyebarilmu.com/mengenalaplikasi-blynk-untuk-fungsi-iot/. Diakses tanggal 19 Agustus 2018.

[20] Kuncoro . 2015. Cara Kerja Komunikasi UART \& USART.

http://nurcahyokun.blogspot.com/2015/03/cara-kerjakomunikasi-usart-dan-uart.html. Diakses tanggal 10 April 2019. 